\title{
Is there any Prognostically Different Subgroup among Patients with Stage IIIC (Any TN3M0) Breast Carcinoma?
}

\author{
NÜvit Duraker, MD, Zeynep C. Çaynak, MD, and Bakır Batı, MD
}

Fifth Department of Surgery, SSK Okmeydanı Training Hospital, Istanbul, Turkey

Erratum to: $10.1245 / \mathrm{s} 10434-007-9558-6$

Annals of Surgical Oncology

The AJCC TNM stage was incorrect as published in the first sentence of the last paragraph of the article titled "Is There Any Prognostically Different Subgroup among Patients with Stage IIIC (AnyTN3M0) Breast Carcinoma?" by Duraker et al (DOI:10.1245/ s10434-007-9558-6).
The correct sentence is:

"In conclusion, we suggest that revision of AJCC TNM classification for breast carcinoma, so that patients with $\mathrm{T} 1,2,3 \mathrm{~N} 3 \mathrm{M} 0$ disease form stage IIIB and patients with T4anyNM0 disease form stage IIIC, will refine the classification." 